\title{
Understanding the Benefits of Product-Service Systems for Parties Involved in Remanufacturing
}

\author{
Anjar Priyono \\ Department of Management, Universitas Islam Indonesia (Indonesia) \\ anjar.prijono@,uii.ac.id
}

Received: August 2016

Accepted: February 2017

\section{Abstract:}

Purpose: This study aims to analyse the benefits of PSS for interested parties in remanufacturing, including manufacturing companies, original equipment manufacturers, and customers. Existing studies examining the Product-Service System (PSS) focus on the relationship between two parties, either between Original Equipment Manufacturers (OEMs) and customers, or between remanufacturers with customers. This study attempts to fill a gap by investigating how the PSS benefits OEMs, remanufacturers and customers.

Design/methodology/approach: This research used a case study method to examine the practical application of PSS in remanufacturing companies. A qualitative approach was employed to analyse emerging phenomena in the case companies, and the researcher collaborated with the involved parties to create new knowledge. Thus, this research study can offer theoretical as well as practical insights.

Findings: All parties involved in PSS consistently gain benefit from adopting the practice. From the perspective of remanufacturers, the major benefit of adopting PSS is that it can help reduce uncertainties regarding the timing, quantity and quality of returned cores. Due to these reduced uncertainties, remanufacturers benefit from higher profitability and more environmentally friendly products. These benefits have multiplier effects on both customers and OEMs. 
Practical implications: This study offers benefits to remanufacturing managers in the sense that it provides guidance for them to better manage remanufacturing operations so that they become more environmentally friendly and profitable.

Originality/value: This study represents the first time that the benefits of PSS in supporting remanufacturing have been viewed from an integrative perspective - i.e. manufacturers, remanufacturers, and customers.

Keywords: remanufacture, product service system, sustainability, operations management, environmental issues, reverse logistics

\section{Introduction}

Remanufacturing is a process of transforming used products into 'like new' products that have the same or higher warranty and quality performance (Ijomah, 2002, 2008). The process has been widely recognised as a form of green production, which is an important aspect of competitive strategy for manufacturing companies (Baines, Brown, Benedettini \& Ball, 2013). The process begins with cleaning, and is followed by a series of steps including classifying, sorting, disassembling, building and testing. Remanufacturing retains physical form and results in high energy savings in comparison to making products from purely virgin materials. To facilitate remanufacture, products should be designed in a such a way that they are durable, remanufacturable, as well as upgradable into newer versions (Sundin \& Bras, 2005). In short, remanufacturing uses less new materials to meet customer needs. Figure 1 presents the overall process of remanufacturing. 


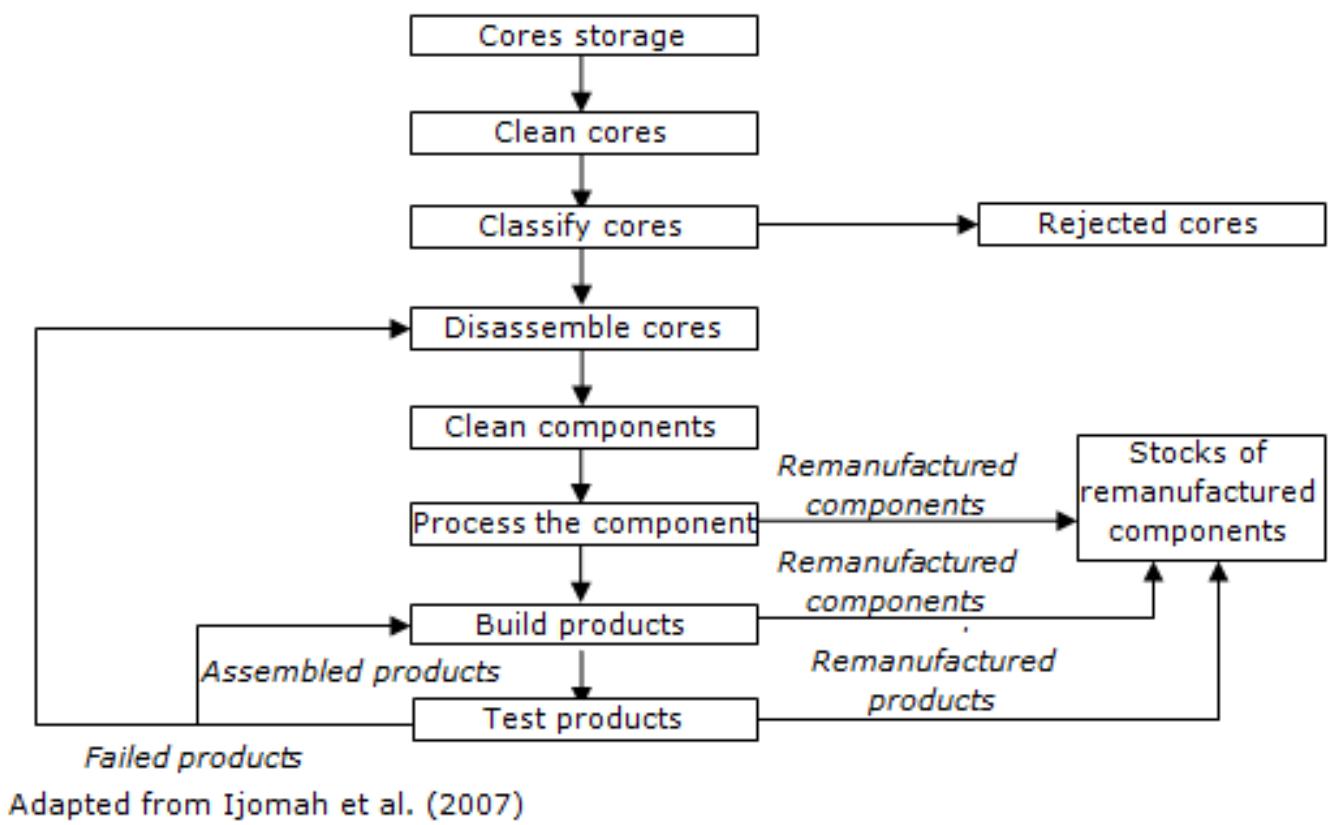

Figure 1. Process of remanufacturing (Ijomah, McMahon, Hammond \& Newman, 2007)

The main problem encountered in remanufacturing is uncertainties regarding the timing, quantity and quality of cores that arrive to factory of remanufacturers. In view of these uncertainties, production planning and control in remanufacturing is more difficult to manage than that in conventional manufacturing (Guide Jr., 2000; Ma, Jun \& Kim, 2011). Guide Jr, Jayaraman, Srivastava and Benton (2000) identified seven characteristics that make production planning and control in remanufacturing more complex in comparison to conventional manufacturing. These include: uncertainty in timing and quantity of returns, balancing demands with returns, the need for disassembly, materials recovery uncertainty, the need for reverse logistics, matching material restrictions, stochastic routings for materials, and highly variable processing times. Information systems and new production planning techniques have been developed in response to this issue, and can help remanufacturers to manage these uncertainties (Guide Jr., Jayaraman, Srivastava \& Benton, 2000).

One recent business model that has been integrated with remanufacturing is the Product-Service System (PSS). PSS refers to a business concept in which manufacturers maintain some sort of 'ownership' over the products they sell to customers (Östlin, Sundin \& Björkman, 2008). Existing literature explains how remanufacturing and PSS support each other. As an example, Mont, Dalhammar and Jacobansson (2006) demonstrated how remanufactured baby prams offered to customers under leasing agreements could avoid the transaction costs of having to sell the prams on the second-hand market. In addition, customers could obtain remanufactured products whose quality was 'like new' at an affordable price. 
There has been growing interest in PSS, as indicated by the increasing number of publications on the topic in recent decades (Beuren, Gitirana, Ferreira \& Miguel, 2013). Moreover, a number of systematic literature reviews in the last couple of years highlight positive results from PSS adoption (Annarelli, Battistella \& Nonino, 2016; Beuren et al., 2013). The majority of past research has found that PSS adoption leads to positive economic results, while the social and environmental aspects have not been sufficiently explored (Beuren et al., 2013).

To support end-of-life strategies, organisations should design products with this in mind. However, the success of end-of-life strategies cannot rely on product design alone; rather, a specific business model and supply chain should be adopted to support product recovery (Gehin, Zwolinski \& Brissaud, 2008). PSS is a business model that has been described in much literature as supporting sustainability (Annarelli et al., 2016). For Original Equipment Manufacturers (OEMs), PSS extends the life of products, provided that the products still meet the criteria set by customers (Sundin \& Bras, 2005). In addition, PSS enables remanufacturers to upgrade products so that the new version of the product can incorporate the latest technology. With the option of upgrading, customers do not need to sell on their old products, and producers could reprocess returned products instead of throwing them away into landfill (Chierici \& Copani, 2016).

However, the motivation for adopting PSS is not always environmental. Renting and leasing are financial instruments that have become widely used to help customers obtain certain products. Typically, this involves a leasing company, as a third party. The third party financing company buys the product from the manufacturer, and customers use leasing to 'consume' the products.

PSS is a complex business model. According to Tukker (2004), there are eight kinds of PSS, which can be broadly categorised into three main types. The first type is product-oriented services. In this type of PSS, the company focuses on selling the products, but also offers some additional services. These additional services can take one of two forms: product-related services, and advice and consultancy. The PSS provider should be responsible for the contracted service (Reim, Parida \& Örtqvist, 2015). This form of business is popular in business-to-business markets where the producers offer extra services to customers as part of their after sales service (Tukker, 2004).

The second type is use-oriented services. Here, the focus of the business is not on selling the physical products, although traditional products still play an important role. The ownership of the products remains with the producers, but is made available in different forms and can be shared with different customers. PSS providers should ensure that the products can be used properly by customers (Reim et al., 2015) Some examples of this business category include product leasing, product renting or sharing, as well as product pooling (Tukker, 2004). 
The third category is results-oriented services, which focus on the results of an agreement, whereby customer and company agree on the results without the involvement of the pre-determined product. The ownership of the product is not transferred to customers, but remains with the company. Services of this type include activity outsourcing, pay per service units, and functional results (Tukker, 2004). In this model, customers only pay for what has been consumed (Reim et al., 2015).

There is a wide variety of different compositions of products and services across the three categories. Product-oriented services have a greater focus on products, while results-oriented services focus more on services (Tukker, 2004). Adding to this complexity is how the PSS can be used to improve the overall remanufacturing process. Although the benefits of PSS for remanufacturing practices have been mentioned in past literature, a detailed investigation of how it affects all parties i.e. OEM, customers, remanufacturers - involved in closed-loop supply chains has been notably missing from previous investigations. Therefore, how and why PSS benefits those parties needs further analysis.

Many studies have examined the benefits of PSS for manufacturing companies. However, most existing research treats the remanufacturing company as an independent entity, without considering OEMs and customers. Moreover, the benefit of remanufacturing for three particular parties has never been investigated, namely OEMs, customers, and remanufacturers. The majority of past studies have consistently concluded that PSS has a positive effect on company performance, customer satisfaction, and competitive advantage (Manzini \& Vezzoli, 2002). However, most of these studies were undertaken in conventional manufacturing contexts. Motivated by this research gap, the present study attempts to analyse how and in what way PSS benefits the parties involved in remanufacturing and closed-loop supply chains.

The focus of previous investigations has predominantly been on the relationship between manufacturing companies and their customers (Figure 2.a). Some studies have examined a slightly different perspective, and have investigated the dyadic relationship between remanufacturers and customers (Figure 2.b).

Meanwhile, analysis from a standpoint that integrates customers, manufacturers and remanufacturers has never been undertaken. The present study uses a broader perspective that integrates customers, manufacturers and remanufacturers in order to analyse how PSS benefits those parties. In this way, the study attempts to fill a gap in the research by addressing an area that it seems has received no academic attention, using an integrative perspective. The integrative perspective of this study is presented graphically in Figure 2.c. 


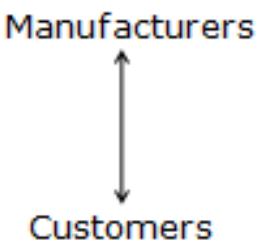

Figure 2.a. PSS in dyadic relationship between manufacturers and customers

\section{Remanufacturers}

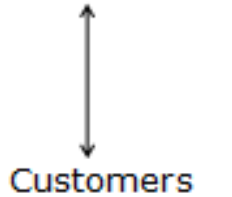

Figure 2.b. PSS in dyadic relationship between

remanufacturers and customers

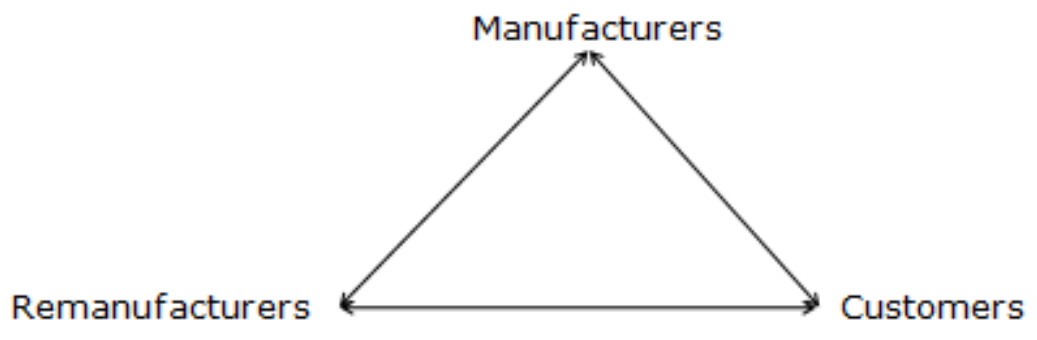

Figure 2.c. PSS in a comprehensive analysis

Figure 2. Various relationships as objects of analysis in existing research

When investigating PSS in remanufacturing, it is also important to consider the different types of remanufacturers. According to Lund (1984), there are three types of remanufacturing companies, as follows:

- OEM remanufacturers: manufacturers that carry out remanufacturing in addition to manufacturing new products.

- Contract remanufacturers: remanufacturers who, under the license of OEMs, carry out remanufacturing of the OEMs' products and often, but not always, receive technical support from the OEMs.

- Independent remanufacturers: parties who remanufacture other people's products without technical support or licenses, for direct sale to the aftermarket.

It seems that existing studies do not distinguish between the different types of remanufacturer, and many assume that the remanufacturer and manufacturer are the same party. Previous research mostly investigated OEM remanufacturers (e.g. Chierici \& Copani, 2016; Sundin \& Bras, 2005; Sakao \& Mizuyama, 2014). However, in practice, the behaviour and capabilities of contract remanufacturers are different from those of OEM remanufacturers. In practice, the three types of remanufacturer have different levels of cores control. Thus, it is relevant to address this issue, as it can offer new 
knowledge in this field. Motivated by this identified research gap, the present study aims to investigate the following research question: How can PSS benefit the parties involved in remanufacturing businesses?

The reminder of this paper will be organised into five sections. The next section will discuss existing studies of the product-service system. Section 3 will explain the research method used in this study, and will be followed by an analysis and discussion in Section 4. The research method justifies the design of this study, and the data collection and analysis techniques will be discussed. The analysis and discussions will explain the benefits of PSS in remanufacturing, as well as the advantages for general business practices. Finally, Section 5 will present the conclusion, summarise the findings, discuss the academic and practical implications of this research, and suggest possible future research trajectories.

\section{The Product-Service System in Current Literature}

A number of definitions of PSS have been provided in the literature (Tukker, 2015), but there is a degree of commonality between them. The key feature of PSS seems to be that it consists of combined products and services aimed at fulfilling the needs of customers during the whole of the product's life cycle. The combination includes infrastructure, networks, and other features to create value that is then offered to customers. The main emphasis of PSS is the functionality of products (Sundin \& Bras, 2005).

In a systematic literature review, Annarelli et al. (2016) reported that Mont (2002) was the first scholar to have successfully provided an integrated definition of PSS in reference to sustainability. According to Mont (2002), PSS is "a system of products, services, supporting networks and infrastructure that is designed to be competitive, satisfy customer needs, and have a lower environmental impact than traditional business models". In comparison with other existing definitions, this definition is the most widely accepted in academia (Annarelli et al., 2016).

The parties involved in the remanufacturing industry can be explained in reference to stakeholder theory. According to this theory, which was proposed by Freemen, Harrison, Wick, Parmar and Colle (2010), the main interested parties in any corporation are the shareholders, management, employees, and customers. This is the group that enters into a direct transaction with companies. In addition, there are parties that do not have a direct relationship with the corporation, such as the government, academia, social activists, and environmentalists. Although this group does not engage in a business transaction with the company, their importance should not be underestimated. 
According to stakeholder theory, environmental and social spending does not necessarily harm economic performance (Freemen et al., 2010). Managing a business responsibly leads to stakeholder satisfaction, which eventually results in sustainable economic performance (Fonseca, Ramos, Rosa, Braga \& Sampaio, 2016). The results of acting responsibly are still meaningful, even during economic downturns (Fonseca \& Ferro, 2016).

In this study, the involved parties are considered to be those that have a interest in the running of the remanufacturing process, namely: OEMs, remanufacturers and customers. These are the parties that determine the success of the remanufacturing process. Information, knowledge, production technology, and core supplies are all under the control of these three parties. Thus, it is important to focus an investigation on these parties. Clarkson (1995) argues that the main stakeholders are likely to have similar interests, because they share goals related to the business transaction. In addition, they might have a clear expectation of how the relationship should be developed, and what should be produced from the relationship. In order for a common expectation to be met, Matos and Silvestre (2013) proposed prerequisites, stating that there should be coordination and trust between the stakeholders. Communication skills are critical to ensure that coordination is effective.

PSS typically serves as a means for remanufacturing companies to develop a relationship with industrial customers. Thus, it involves inter-organisational relationships between remanufacturers and industrial customers. Strong relationships between buyers and users in PSS makes remanufacturing more profitable (Östlin et al., 2008; Sundin \& Bras, 2005). The natural resources required to meet demands from the market are limited, and are not sufficient to fulfil the needs of the overall population, due to its size. Accordingly, there is an urgent need to change how people utilise these resources; PSS is one such method that can support a closed-loop economy.

Using PSS, companies will have better control over the products sold to customers, and thus are better able to fulfil customers' needs. PSS also helps remanufacturers to obtain information regarding returned products, such as when and how many products will be returned to remanufacturers, which can improve the remanufacturing process (Sundin \& Bras, 2005).

Examining PSS in the context of remanufacturing has the ability to produce a holistic analysis, rather than investigating either concept alone. This is due to the fact that PSS requires an interdisciplinary approach (Sakao \& Mizuyama, 2014). PSS has been widely adopted across different industries, and is not limited to remanufacturing. This is due to the increasing number of firms offering a combination of products and services. For example, in the USA and Finland, the figure of PSS offering is more than $50 \%$ of all manufacturing industries (Neely, 2007). 
There are various different types of relationship between remanufacturing companies and cores suppliers. Each type of relationship has a number of different consequences, and therefore creates different problems for remanufacturing companies (Östlin et al., 2008). Östlin et al. (2008) argue that PSS is the relationship that offers the most control over cores arrival, and that it therefore reduces the uncertainity around cores arrival, quality and quantity. In addition to this, various forms of PSS can be utilised by remanufacturing companies to manage their cores supplies.

\section{Research Method}

This research aims to contribute novel knowledge by identifying the benefit of PSS for parties involved in remanufacturing. To this end, this research utilised a case study method to develop a theory, as suggested in existing literature (Eisenhardt \& Graebner, 2007; Eisenhardt, 1989; Yin, 2009). As explained by Yin (2009), case study research requires the investigator to acquire some preliminary knowledge of the field. For this reason, a number of company visits were undertaken to select subjects relevant to the objectives of the study. The majority of studies in the field of remanufacturing have utilised positivist paradigms, using operations research and making assumptions that are difficult to represent real life situations (Flynn, Kakibara, Schroeder, Bates \& Flynn, 1990). Accordingly, using a different research methodology and philosophical stance would provide a significant contribution to existing knowledge.

The inclusion of companies as subjects in the study was based on their potential for enabling replication logic, not statistical generalisation (Yin, 2009). The researcher decided to use a multiple case study research design as opposed to a single case design, for several reasons. First, multiple cases are more likely to generate testable and empirically valid theory (Eisenhardt, 1989), and second, the boundary between the phenomena, subjects and contexts under which PSS is in use are not easily identified (Yin, 2009).

After a number of company visits, two companies were considered to be appropriate for the purposes of this study. Both case studies had implemented pay per service units used by customers. According to the classification by Tukker (2004), this type of PSS is categorised as a results-oriented service that focuses on the output of the product, according to the level of use. A brief description of the two case companies is presented in Table 1 below. 


\begin{tabular}{|c|c|c|c|}
\hline No. & Company & PhotoCopier Co. & Jet Engine Co. \\
\hline 1. & Location & Glasgow, UK & Glasgow, UK \\
\hline 2. & Customers & $\begin{array}{l}\text { Industrial customers, such as educational } \\
\text { institutions, government bodies, and private } \\
\text { companies. }\end{array}$ & Airline companies, and governments. \\
\hline 3. & Established & $\begin{array}{l}\text { 1994. The company has been an OEM } \\
\text { remanufacturer for photocopiers since } 2011 . \\
\text { It was an independent remanufacturer } \\
\text { before being acquired by Xerox. }\end{array}$ & $\begin{array}{l}\text { 1953. The company is a subsidiary of a } \\
\text { global jet engine manufacturer specialising in } \\
\text { remanufacturing. Remanufacturing is carried } \\
\text { out by the company as part of MRO } \\
\text { (Maintenance, Repair and Operations). }\end{array}$ \\
\hline 4. & Volume of production & 40-45 copy machines per month. & 370 jet engines per year. \\
\hline 5. & Company size & 43 people. & 625 people. \\
\hline 6. & Mode of agreement & Pay-per-copy. & Power-by-the hour. \\
\hline 7. & Redistribution channel & $\begin{array}{l}\text { Closed-loop supply chain, private } \\
\text { redistribution channel. }\end{array}$ & $\begin{array}{l}\text { Closed-loop supply chain, private } \\
\text { redistribution channel. }\end{array}$ \\
\hline
\end{tabular}

Table 1. Details of the case companies

In the next stage, action research (Platts, 1993) was used to identify and refine the benefits of PSS in the context of remanufacturing, as they relate to the three parties: manufacturing companies, remanufacturers and customers. This method was used as it was deemed suitable for creating knowledge as well as providing solutions to emerging problems (Susman \& Evered, 1978).

Data collection and analysis were undertaken simultaneously to enable the researcher to make any required changes to the data collection instrument. Collecting additional data was also possible, in case any new supporting data was needed (Eisenhardt, 1989). Interviews, observation and company visits were carried out in order to collect the data. Managers, supervisors and shop floor workers participated as the main data sources, due to their expertise in regard to remanufacturing processes and PSS in the case companies. The use of multiple data collection techniques and data sources was intended to enable the researcher to undertake data triangulation (Yin, 2009). A detailed summary of the data collection techniques is presented in Table 2 below.

\begin{tabular}{|c|c|c|c|}
\hline $\begin{array}{c}\text { Data collection } \\
\text { techniques }\end{array}$ & $\begin{array}{l}\text { Frequency } \\
\text { and duration }\end{array}$ & Focus of investigation & Informants \\
\hline \multicolumn{4}{|c|}{ Case Company 1: PhotoCopier Co. } \\
\hline $\begin{array}{l}\text { - Classroom presentation } \\
\text { - Shop floor visit } \\
\text { - Observation and interview } \\
\text { - Document checks }\end{array}$ & $\begin{array}{l}\text { Four visits, } \\
\text { ranging } \\
\text { from } 2 \\
\text { hours to } 1 \\
\text { day. }\end{array}$ & $\begin{array}{l}\text { - Business operations } \\
\text { - Remanufacturing process in general } \\
\text { - Production planning and control } \\
\text { - Managing relationships with customers }\end{array}$ & $\begin{array}{l}\text { - General manager } \\
\text { - Disassembly shop floor staff } \\
\text { - Testing shop floor staff } \\
\text { - Reassembly shop floor staff }\end{array}$ \\
\hline \multicolumn{4}{|c|}{ Case Company 2: Jet Engine Co. } \\
\hline $\begin{array}{l}\text { - } \text { Classroom presentation } \\
\text { - Discussion } \\
\text { - Documentation } \\
\text { - Interview and discussion } \\
\text { - Shop floor observation }\end{array}$ & $\begin{array}{l}\text { - Five visits, } \\
\text { ranging } \\
\text { from } 1 \\
\text { hour to } 1 \\
\text { day. }\end{array}$ & $\begin{array}{l}\text { - Remanufacturing process in general } \\
\text { - Production planning and control } \\
\text { - Company business operations } \\
\text { - Managing relationships with customers }\end{array}$ & $\begin{array}{l}\text { - } \text { Commercial director } \\
\text { - Shop floor supervisors (2) } \\
\text { - Rebuild staff } \\
\text { - Inspection staff (2) }\end{array}$ \\
\hline
\end{tabular}

Table 2. The details of data collection 


\section{Case Studies}

\subsection{Case Study 1: PhotoCopier Co.}

\subsubsection{The Company and Business}

PhotoCopier Co. began as a photocopier remanufacturing business in 1994. In 2011, the company was acquired by Xerox, a global photocopier manufacturing company. Other than managing its facility located in Glasgow, United Kingdom the company office in Glasgow manages another facility, located in Aberdeen, United Kingdom. Its customers, who are mostly industrial customers, develop a relationship with PhotoCopier Co. based on a pay-per-copy system. With the support of 43 employees, the company delivers approximately 40 remanufactured photocopiers per month, across a wide range of models. Through their remanufacturing, the company can recover $70-90 \%$ of the machine components.

Typical uncertainties encountered within photocopier remanufacturing include: when the products are returned (time uncertainty), in what condition (quality uncertainty), and how many (quantity uncertainty). The many model variants in photocopiers add to these uncertainties. In addition, different customers require different product models, making accurate forecasting difficult.

\subsubsection{Closed-Loop Supply Chain}

PhotoCopier Co. utilises a closed-loop supply chain. The company manages its own distribution network to distribute remanufactured photocopiers and take back used products. The forecast of cores arrival is conducted by looking at historical data available within the company. For this reason, cores arrive at the facility more predictably. Several advantages of offering PSS to customers as a part of a remanufacturing programme include: (1) cores arrival becomes more predictable; (2) employees who remanufacture the photocopiers do not need to acquire new skills as they are remanufacturing the same product models; and (3) easier identification of problems due to product history availability.

\subsubsection{Cores Sorting}

PhotoCopier Co. selects only certain photocopier models to be remanufactured, because some models are not suitable for remanufacturing, and will only cause problems in the future if they are remanufactured. In addition to selecting certain models for remanufacturing, the company organises the sorting of cores that arrive at the factory. The purposes of the sorting are to: (1) assess the potential cost of remanufacture; and (2) estimate the potential sales price of the remanufactured products. 


\subsubsection{Electronic Instruments to Record Customer Use Pattern}

An instrument is attached to the photocopiers that provides information about the historical use of the product. This instrument is useful for remanufacturing, as one manager explained:

"We can go in electronically and interrogate the machine. So, we can go into engineer access code, and say 'tell me the life that the drum has done. Tell me the life the fusion section has done, and how many paper jams the machine has had, tell me when these paper jams have occurred in the machine.' So, it gives us areas to address..."

The device helps employees to decide whether the components should be replaced with new ones. The company will decide to use components again if the remaining value is high.

\subsubsection{Knowledge Sharing}

PhotoCopier benefits from a knowledge transfer with its parent company regarding product specifications. In return, PhotoCopier Co. provides feedback to its parent company regarding the products' performance and improvement in the products' remanufacturability.

\subsection{Case Study 2: Jet Engine Co.}

\subsubsection{The Company and Business}

Jet Engine Co. is part of a global jet engine manufacturer undertaking remanufacturing services as part of its maintenance, repair and operations procedures. The company is supported with 600 staff for service delivery to over 120 customers. It offers a product-service package, whereby airlines purchase the service from the company based on 'power by the hour'. The rate of 'power by the hour' - i.e. a fee agreed with the airline regarding the cost for an engine for a one-hour flight - is determined by various factors that constitute 'product attribute data'. These attributes determine the risk of potential engine failure, such as the age of the engine, the type of engine, or the location of operations.

The remanufacturing process of jet engines starts when the company receives information regarding cores condition from the Engine Health Management System (EHMS). The information received from the EHMS, which is combined with data from the log-book, is used to identify the resources required for remanufacturing. At this point, it is possible for the company to decide to postpone cores arrival and keep the engine flying. This situation occurs when the company does not have the required resources to remanufacture the engines. 


\subsubsection{Sources of Uncertainty}

The cost of remanufacturing, which ranges from $f 23,000$ to $£ 30,000$, depends on various factors, which can be identified accurately for each engine. The high variance in the remanufacturing cost is caused by uncertainties found in cores. The summary of the causes of uncertainties is presented in Figure 3, and followed by a discussion.

Flight cycles refers to the use of an engine for a single take-off and landing of an aircraft. The damaged parts of engines are different in engines that have been used in longer flights, but less frequently, and engines used for more frequent but shorter flights. Engines that operate for short distance flights have longer flight cycles and their life-limited parts require more frequent replacement. Thus, engines with longer flight cycles incur higher remanufacturing costs due to the need for more replacement parts.

The age of the engine affects the number of damaged components and the type of damage caused by various parts. Old engines typically require more work, due to the higher number of parts needing replacement.

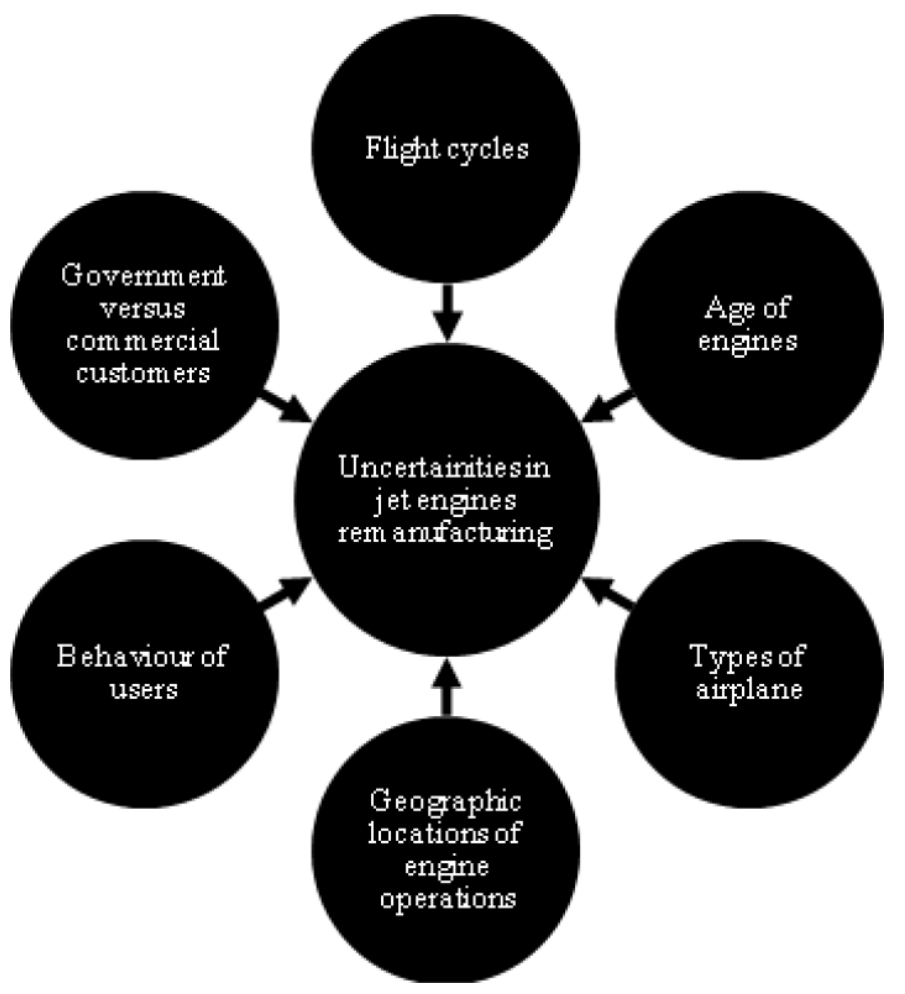

Figure 3. Sources of uncertainty in jet engine remanufacturing 
Type of airplanes causes a lot of variance in remanufacturing costs. For example, when a V2500 is installed in the Airbus 318 or 319, it produces 22,000 thrust, while the same engine installed in the Airbus 321 produces 33,000 thrust. The same engine installed in the Airbus 321 produces 50\% more thrust and, consequently, affects the remanufacturing costs due to the greater number of components needing replacement.

The geographic location of engine operators causes further variation in remanufacturing cost. For example, airplanes operating in oceanic areas experience different problems compared to those that fly over desert areas. The large amount of salt in the air in oceanic areas causes some problems with certain components of the engines. Meanwhile, the dust that causes other problems in the engine components of airplanes that operate in desert areas. As a result, the components of jet engines that need to be replaced with new ones are not always the same. Other conditions that may cause problems include the temperature and humidity of the environment the engines are operating in.

The behaviour of users is difficult to forecast, since each customer has different preferences. For example, some pilots tend to reduce thrust in certain weather conditions, but others are more likely to increase it. These differences cause variances in the number of damaged parts, and thus the need for replacement.

Commercial and government customers have different patterns of use. For instance, governments are less sensitive to cost because the budget for the engine maintenance has already been allocated. Thus, incoming cores from governments are more stable, as they are not affected by seasonal patterns. Meanwhile, cores from commercial customers show some seasonal trends. For example, the jet engines used for small planes are usually rented during the summer, and then remanufactured at the end of the holiday season.

\subsubsection{Engine Health Management System (EHMS)}

The company relies on data retrieved from the EHMS to manage uncertainties during the remanufacturing process. The system provides some indicators to identify potential damage, problems and any works that may be necessary before the engines arrive at the facility. To support the EHMS, the engine is fitted with roughly 25 sensors identifying different indicators, which are then transferred to the pilot and ground staff. The critical engine characteristics that are included in the parameters are the temperatures, pressures, speed, flows and vibration levels. The EHMS monitors whether those parameters are still within the tolerance level and, if not, it can provide some advice on and explanation of these issues. 


\subsubsection{Knowledge Sharing}

Jet Engine Co. receives support from its parent company, which manufactures new jet engines. Product specifications, engine manuals and testing standards are amongst the knowledge that is transferred from the parent company to Jet Engine Co. However, the knowledge provided by the OEMs is sometimes not applicable to remanufacturing.

\subsubsection{Knowledge Exchange Facilitated by PSS}

When remanufacturing companies offer product-service systems to customers, they have to ensure that the products function normally during the contract period. During the contract period, Jet Engine Co. gathers and accumulates knowledge about the product. As a result, the remanufacturers become more knowledgeable about products throughout their lifespans.

\subsubsection{Product Information Database}

Jet Engine Co., as the PSS provider, is significantly supported by the product information database. Jet engines can be remanufactured roughly nine times in their life cycle. To support the remanufacturing process, Jet Engine Co. uses the product history, recorded and stored in the product information database. The information in the system predominantly comes from two sources: the EHMS and the engine log-book.

\section{Findings}

\subsection{PSS and the Practice of Remanufacturing}

The analysis of the data revealed that switching from selling new products to providing purely utility or functionality is not easy task. For this reason, PhotoCopier Co. still sells new products to customers in addition to offering remanufactured products. Persuading customers to switch to pure PSS is a challenge. Customers realise that integrated PSS is preferable from environmental perspective, but convincing them of the economic benefit is more difficult. These findings support existing conclusions that PSS is preferred from both an environmental and economic perspective (Mont, 2004). This evidence can motivate OEMs to design products that are durable, have low maintenance costs and long life times. Evidence for this was found in both case companies in this research. 
There are at least two supporting conditions for adopting PSS in jet engines and photocopiers: first, both product types are functional products, and second, there is no concern that remanufactured products will cannibalise the sales of new products Rather, both case companies attempt to maximise the economic benefit over the life of the products.

The major environmental benefit of PSS, as observed in the two case companies, is that it reduces amount of waste thrown into landfill. This was particularly evident in the case of photocopiers. On the other hand, material recycling is unlikely to occur with jet engine products, where engines will be used until the end of their life span. Thus, the main environmental benefit comes from the extended life of the products.

The two case studies demonstrated that PSS can be integrated with computer systems in remanufacturing facilities. This integration is beneficial, as it can be used to minimise the level of stock held at the remanufacturing facility. The company will only remanufacture products when necessary, and all remanufactured products will be dispatched to customers.

PhotoCopier Co. uses private reverse supply chain networks. The company relies on its own local supply chain area network to collect and redistribute products from customers. This strategy is intended to keep costs at a minimum level. Other customers located in other regions are serviced by other company branches. A centralised reverse supply chain network offers economies of scale, but it require high transportation cost.

In Jet Engine Co., the integration of PSS into remanufacturing process offers a number of benefits, including early notification of when and how many products will be returned. This information makes the remanufacturing process easier to plan, schedule and manage. The Engine Health Monitoring and Engine Control System used by Jet Engine Co. helps to identify problems during engine operations, which are documented so that potential failures can be identified earlier.

The adoption of PSS in Jet Engine Co. thus enables a learning process. Problems that occur during the engine operation are documented so that potential failure can be identified earlier. This makes the remanufacturing process run more efficiently. Although the engines are operated by airline companies, the case company can gain access to relevant information; this might not occur if the case company and airline operators had not signed a PSS agreement.

This study demonstrate that adoption of ecodesign offers benefits for companies adopting PSS. Products that are designed according to eco-principles have lower remanufacturing costs (Hatcher, Ijomah \& Windmill, 2011). This is important, because companies have little incentive to remanufacture unless the products have been designed for remanufacturing (Sundin \& Bras, 2005). The high value of jet engines, 
which are produced via an advanced and complex manufacturing process, makes remanufacturing interesting because the cost of remanufacturing is much lower than the production of new products. Thus, jet engine manufacturers have a real incentive to adopt ecodesign principles when developing their products.

Nevertheless, the manufacturers of jet engines appear to be ignoring eco-design principles, as the focus is on product reliability, safety and specifications, although the case company is still eager to remanufacture. In this industry, flight safety issues are more important than environmental issues; accordingly, the company must compromise on remanufacturing in order to prioritise safety issues.

There are several lessons that can be learned from the case studies related to the adoption of PSS in relation to information. Information plays a critical role in remanufacturing complex products (Ferrer \& Ketzenberg, 2004); it is used to estimate costs, avoid remanufacturing process failures, and reduce the lead time for new part procurement. In Jet Engine Co., it was found that cost savings can be achieved through the support of the information system, which is a part of PSS.

PSS benefits greatly from the EHMS. The EHMS improves the capability of the company to identify failures, which in turn leads to more selective and cost effective engine strip procedure and piece part replacement. By using the Engine Health Monitoring and Engine Control System, problems during engine operations are documented so that potential failures can be identified. However, there are other sources of variation, meaning failure cannot be predicted entirely accurately.

Companies could decide to reject incoming cores due to their being low quality, which can make remanufacturing economically unfeasible (Ferguson, Guide Jr., Koca \& Souza, 2009). In such a situation, under the PSS agreement, the parent company should provide a new engine as a replacement for the older one. This strategy occurs PhotoCopier Co. Thus, undertaking remanufacturing activities on poor quality cores can be avoided.

PSS provides a further benefit in the form of employee skill maintenance and development. In Jet Engine Co., skills can diminish if employees have not carried out certain tasks for a certain period of time. This skills are assessed based on the standards from regulatory bodies, such as the International Aviation Safety Assessments (IASA), the Civil Aviation Authority (CAA), and the European Aviation Safety Agency (EASA). Employee skills can be developed from experience and accumulated over time. This is facilitated by PSS because employees at the company remanufacture the same type of jet engine models during the contract periods.

In summary, PSS provides benefits to both companies and customers, as it helps improve company profitability and competitiveness, as well as satisfying customers' needs, while minimising environmental 
impact. Remanufactured products that are sold through PSS enable better control over their return. Companies can more accurately forecast when the products will be returned to the company. In addition, using a PSS can avoid the unnecessary cost of recycling electronic products like copier machines.

\subsection{Benefits of PSS in Remanufacturing Operations}

PSS offers several advantages for the remanufacturing process, as well as for business practices in general. Many studies have mentioned the benefit of PSS with regard to sustainability, but none have explained the benefit for remanufacturing processes and business operations in detail. Table 3 summarises the benefits of PSS with regard to the remanufacturing process, and further details are provided in the subsequent discussion.

\subsubsection{Closed-Loop Supply Chain and Cores Sorting}

The case companies' leasing agreements create a closed-loop supply chain, which can hinder any independent remanufacturers entering the business. For example, approximately $90 \%$ of Trent 700 jet engines operated by airline companies are under a power-by-the hour contract and, consequently, those engines are returned to Jet Engine Co. There is a small opportunity for other parties to claim the remaining $10 \%$ of the market. The need for high cost investment is also a reason why independent remanufacturers are not able to enter the jet engine remanufacturing business.

In traditional remanufacturing operations, cores sorting must be carried out, but this is not the case for companies that offer PSS. From the perspective of remanufacturing operations, PSS can substitute the function of cores sorting. The early information regarding cores that is available in closed-loop supply chains enables companies to decide whether to accept or reject incoming cores.

\subsubsection{Early Identification of Damaged Parts}

Using the information that is available from the EHMS, Jet Engine Co. is able to identify any damaged parts, so that it can order new parts for replacement. As mentioned previously, the data available in the EHMS is captured by sensors attached to the jet engines. Meanwhile, in PhotoCopier Co., the parts commonly damaged in photocopiers are documented, and the company can prepare the new parts for replacement in advance, before the cores arrive at the company facility. 


\begin{tabular}{|c|l|l|l|}
\hline No. & \multicolumn{1}{|c|}{ Benefit of PSS } & \multicolumn{1}{|c|}{ PhotoCopier Co. } & \multicolumn{1}{|c|}{ Jet Engine Co. } \\
\hline 1. & $\begin{array}{l}\text { Substitution for cores } \\
\text { sorting. }\end{array}$ & Forecasting supported by historical data. & EHMS supported by database. \\
\hline 2. & $\begin{array}{l}\text { Early identification of } \\
\text { damaged parts. }\end{array}$ & $\begin{array}{l}\text { Parts that are commonly damaged are } \\
\text { documented and the company can prepare } \\
\text { new replacement parts. }\end{array}$ & $\begin{array}{l}\text { Indicators produced by sensors attached to } \\
\text { the jet engines provide some indications of } \\
\text { which components require replacement. }\end{array}$ \\
\hline 3. & $\begin{array}{l}\text { Reduced idle capacity and } \\
\text { more optimum capacity } \\
\text { utilisation. }\end{array}$ & $\begin{array}{l}\text { Resources can be better managed due to } \\
\text { more predictable cores arrival. }\end{array}$ & $\begin{array}{l}\text { It is extremely difficult to carry out jet } \\
\text { engine remanufacture without any support } \\
\text { from the EHMS. }\end{array}$ \\
\hline 4. & $\begin{array}{l}\text { More optimum human } \\
\text { resource allocation. }\end{array}$ & $\begin{array}{l}\text { Remanufacturers manage new part } \\
\text { procurement and employee skills more } \\
\text { easily. }\end{array}$ & $\begin{array}{l}\text { Remanufacturers manage new part } \\
\text { procurement, employee skills, equipment, } \\
\text { and new parts for product reasssembly } \\
\text { more easily. }\end{array}$ \\
\hline 5. & $\begin{array}{l}\text { Better ability to meet } \\
\text { customer demands. }\end{array}$ & $\begin{array}{l}\text { Long-term contracts under PSS enable } \\
\text { remanufacturers to carry out joint forecast, } \\
\text { product upgrade, and have a better } \\
\text { understanding of customers' needs. }\end{array}$ & $\begin{array}{l}\text { Long-term contracts under a PSS scheme } \\
\text { enable remanufacturers to undertake joint } \\
\text { forecast, product upgrade, component } \\
\text { borrowing between products, and have a } \\
\text { better understanding of customer needs } \\
\text { through accumulated data (product } \\
\text { log-books and product history). }\end{array}$ \\
\hline
\end{tabular}

Table 3. Summary of the benefits of PSS for remanufacturing operations

\subsubsection{Reduced Idle Capacity, More Optimum Capacity Utilisation and Human Resource}

\section{Allocation}

PSS facilitates intensive communication between remanufacturers and customers. This communication and joint forecast with customers helps remanufacturers to develop a more accurate production plan. Joint forecast enables both case companies to better predict when, how many, and, to some extent, in what condition cores would arrive at the companies' facilities. Continuous communication with customers results in a mutual understanding between both parties. As a result, production capacity is better utilised and more optimum human resource allocation can be achieved.

\subsection{The Benefits of PSS Beyond Remanufacturing Practices}

PSS is commonly associated with environmental issues, but it is necessary to discuss PSS from a broader perspective, and in particular how PSS can contribute toward more profitable business operations (Mont $\&$ Tukker, 2006). The benefits obtained from the empirical findings presented in this study are not related to the remanufacturing process directly, but they offer benefit to the two case companies in general, as discussed below. 


\subsubsection{Intellectual Property Rights Protection}

From the perspective of OEMs, carrying out remanufacturing in-house is a way of protecting their intellectual property rights (IPR) (Martin, Guide Jr. \& Craighead, 2010) and to prevent independent remanufacturers from entering the after-market business (Lind, Olsson \& Sundin, 2014). This study has demonstrated that the private reverse supply chains organised by both case companies largely prevents independent remanufacturers from obtaining cores from customers. There are a lot of IPRs embedded in photocopiers and jet engines. When photocopiers and jet engines are disassembled, the IPRs inside the products are subject to exposure if the case companies hire contracted remanufacturers. A photocopier is an electromechanical product containing a high level of proprietary technology. Similarly, producing jet engines requires advanced manufacturing technology. The empirical findings of this study show that PSS not only protects the products within the companies' control, but also mitigates IPR-related risks.

\subsubsection{Knowledge Exchange Between Remanufacturers and Manufacturers}

PSS supports knowledge exchange between manufacturers and remanufacturers. This kind of exchange is extremely rare in contract and independent remanufacturing, due to the reluctance of OEMs to share knowledge, since it might endanger their intellectual property (Martin et al., 2010; Subramoniam, Huisingh \& Chinnam, 2009).

Manufacturers can design more environmentally friendly products by incorporating knowledge that they have gained from remanufacturers (Ferrer \& Whybark, 2000). This knowledge is unique and cannot be obtained from other parties, only from remanufacturers, as the ones creating the knowledge (Lind et al., 2014). This knowledge could potentially be lost unless it is used by manufacturers. The empirical findings of this study show that PSS facilitates knowledge transfer from remanufacturers to manufacturers. Data from the remanufacturing process within PhotoCopier Co. is provided to the new product development team, so that future product generation can be improved. The most commonly damaged parts, product durability, and most frequently emerging errors are among the data transferred to the new product development team. 


\subsubsection{Better Ability to Meet the Demands of Customers}

Chierici and Copani (2016) state that one of the obstacles to PSS is the aesthetic fitness of the product. However, all participants in this study agreed that they are not concerned about this issue. Products are remanufactured during their life cycle with minimum aesthetic impact. For example, PhotoCopier Co. offer product upgrades during the contract periods. If a product upgrade occurs, customers will receive photocopiers with a higher product specification halfway through the lease agreement. Under this scheme, PhotoCopier Co. holds a full record of the machine's history, which can help it to maintain the photocopiers, upgrade, and remanufacture them. This scheme also saves the customers money, as they do not have to purchase an entirely new photocopier. Product upgrade is not possible if the company and its customers are not involved in a PSS scheme. Meanwhile, Jet Engine Co. offers modification to customers who have custom needs and requirements.

\subsubsection{More Environmentally Friendly Business Practices}

There are several reasons why PSS creates more environmentally friendly products and business practices. First, PSS helps remanufacturers to better forecast cores arrival, which enables the remanufacturing process to run more efficiently. PhotoCopier Co. can forecast more accurately when and what type of copy machine would be returned by customers; as a consequence, it can reduce the amount of waste it throws into landfill. A long-term relationship with customers under a PSS agreement, supported by a closed-loop supply chain, makes this forecast easier.

From the standpoint of the company, PSS can help the OEM to develop next generation products that are more environmentally friendly. The empirical evidence for this benefit was apparent in Jet Engine Co. Two-way communication between OEMs and remanufacturers has made the integration of design for remanufacturing during product development easier. Design for remanufacture can alter product structure so that cores are more easily disassembled, and reduce damage to parts during the remanufacturing process. In jet engine remanufacturing, damaged parts cost a lot of money. Using feedback from employees working on the disassembly shop floor, new product designers could design new generation products that are easier to disassemble. 


\subsection{Benefit of PSS for Involved Parties}

Many processes in remanufacturing depend to a large extent on both product type and usage patterns (Sundin \& Bras, 2005). PSS offers benefits not only to customers who use the products and remanufacturers who reprocess the returned products, but also to the OEMs who produce the new products. The advantages of PSS for the different parties involved in remanufacturing process are presented in Figure 4.

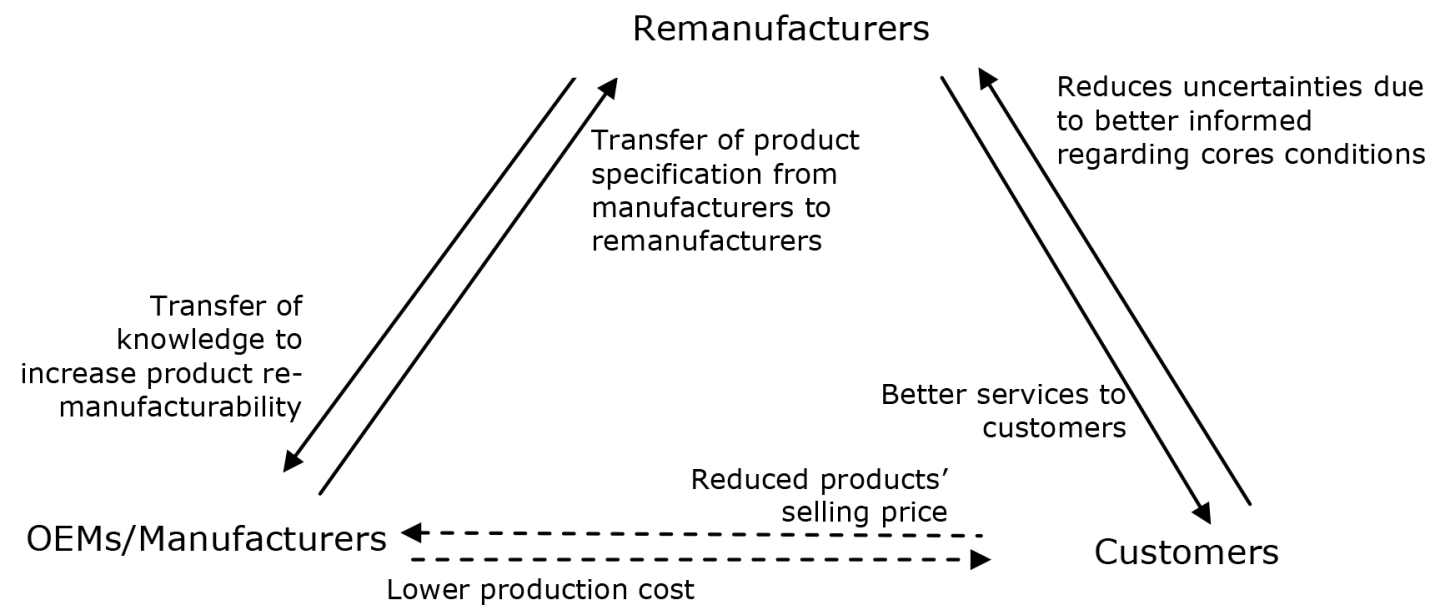

Figure 4. Benefits of PSS for actors involved in remanufacturing

From the perspective of customers, they benefit from PSS through OEMs and remanufacturers. Customers receive better services from remanufacturers because the companies have a better understanding of customers' needs and wants. Despite the fact that OEMs do not interact with customers directly, customers still gain benefits from them as a result of PSS adoption. For this reason, the benefits are indirect, indicated with a dotted-line in Figure 4.

Meanwhile, OEMs benefit from PSS as they receive feedback from remanufacturers regarding product performance. Thus, remanufacturers can identify parts that typically cause problems during product usage. For example, PhotoCopier Co. provides feedback to its parent company, which manufactures new photocopiers, regarding components that typically cause paperjams. Thus, OEMs do not need to obtain firsthand knowledge from customers. This knowledge is also useful in increasing the remanufacturability of the products.

OEMs receive knowledge support from remanufacturers. There are some examples of knowledge created by remanufacturers that is useful to OEMs, particularly regarding product design. The most commonly mentioned issue throughout the course of this study concerned product disassembly. OEMs could alter 
the structure of the product design in order to make products easier to disassemble, and thus reduce the remanufacturing cost.

The lessons learned from the remanufacturing process can be transferred to manufacturers as an input during the redesigning process of new products. For example, standardising the joining of the parts will reduce labour time, as most of tasks in the remanufacturing process are carried out manually. Simply using a standard size of screws could reduce the number of component inventory. The use of standardisation also avoids the need to switch to other tools when disassembling different components.

This study found that product complexity affects the degree of usefulness of the feedback provided by remanufacturers to OEMs. Highly complex products like jet engines have more constraints on how much the design can be altered, and security issues are more important than environmental issues. Thus, the company has to compromise on the importance of DfRemanufacturing to prioritise safety issues.

In return, OEMs provide assistance to remanufacturers by transferring knowledge regarding new product specifications. This transfer is important because in many cases the remanufacturer is a separate entity from the manufacturing division, although they are both part of the same corporation. The support that is gained by remanufacturers is not only obtained from OEMs. Adopting PSS enables the remanufacturers to receive support from customers too, reducing uncertainties by being better informed regarding cores condition. Continuous contact with customers throughout the contract period facilitates information collection regarding cores condition.

\section{Conclusion, Implications and Future Research Trajectories}

This final section will presents the conclusion, which constitutes a summary of the analysis results, the theoretical and practical implications, as well as possible future research directions.

To conclude, PSS provides benefits to three parties involved in the remanufacturing process: remanufacturing companies, customers, and OEMs. The benefits PSS offers to remanufacturers include acting as a substitute for cores sorting, early identification of damaged parts, and reduced idle capacity, amongst other considerations. These benefits come from the customers. In addition, remanufacturers also receive transfer product knowledge from OEMs. Thus, PSS enables remanufacturers to run production processes more efficiently. From the customer's perspective, the benefits include the reduced price of products, continually up-to-date products and availability of supporting services. These benefits are received from both remanufacturers and OEMs. On the other hand, OEMs also receive benefits from the remanufacturers, through knowledge transfer regarding product specification, enabling them to increase remanufacturability. 
From a theoretical perspective, this study has a number of implications, and offers insights that contribute to debate among academics in this field. This study provides empirical evidence that PSS offers a solution to a dispute as to whether or not OEMs should adopt design for remanufacturing (Wu, 2012, 2013). OEMs are currently reluctant to carry out remanufacturing activities, instead focusing on manufacturing new products (Ferguson \& Toktay, 2006). Although the adoption of design for remanufacturing helps them to repair, maintain and disassemble products, it is not always beneficial for them (Wu, 2012, 2013). The adoption of design for remanufacturing may increase the manufacturing costs, which is not good from a manufacturing perspective. On the other hand, it reduces remanufacturing costs, increases component interchangeability and, eventually, reduces the sales price of remanufactured products (Wu, 2013). In short, the adoption of design for remanufacturing poses a dilemma for OEMs.

PSS has the capacity to solve this dilemma, particularly in the case of complex products. It enables remanufacturers to retain some form of ownership and control over their products. For this reason, the adoption of design for remanufacturing offers a benefit to OEMs, since the cores will be returned to and remanufactured by them. In addition, the complexity of products creates certain barriers for independent remanufacturing, due to the need for product knowledge (Hammond, Amezquita \& Bras, 1998). However, OEMs are in a better position to access cores from customers in comparison to independent remanufacturers (Sherwood, Shu \& Fenton, 2000). Compared to simple products, complex products are more likely to involve intellectual property rights, and thus OEMs have an interest in protecting these (Martin et al., 2010; Subramoniam, Huisingh \& Chinnam, 2010). Offering PSS to customers, deciding to remanufacture products in-house, and keeping the products within the control of OEMs are wise strategies to protect intellectual property.

For managers, this study has some practical implications. In order to achieve successful implementation of PSS, the involved parties must cooperate. Although at some point the interests of the different parties might conflict, they should put aside self-interest and prioritise collective action. To this end, PSS requires commitment and behavioural changes from the parties involved. In addition, the inclusion of service in the products implies that OEMs will sell a lower number of products and undertake more service activities. Customer relationships will thus play a more important role in PSS contracts in comparison to conventional manufacturing.

This study recommends two directions for future research. First, there should be a more accurate evaluation of the adoption of the PSS business model. To be more specific, future research could analyse the economic benefit of PSS adoption using a quantitative method. Another alternative is that future research could benchmark the adoption of PSS against a conventional business model, in order to paint a more accurate picture of the economic benefit of PSS. Second, future research might undertake an 
examination of PSS from a comprehensive and strategic perspective. PSS has shifted the focus of companies from how to manufacture products to how to fulfil customers' needs. Consequently, the analysis of future research should emphasise a business system rather than a production system. Future research could examine PSS from a strategic perspective to study the interplays between the PSS business model, competitiveness and collaboration. Such studies could offer a more comprehensive picture of how PSS affects competitiveness, involving various parties related to its implementation - i.e. customers, remanufacturers and OEMs.

\section{References}

Annarelli, A., Battistella, C., \& Nonino, F. (2016). Product service system: A conceptual framework from a systematic review. Journal of Cleaner Production, 139, 1011-1032. https://doi.org/10.1016/j.jclepro.2016.08.061

Baines, T., Brown, S., Benedettini, O., \& Ball, P. (2013). Examining green production and its role within the competitive strategy of manufacturers. Journal of Industrial Engineering and Management, 5(1), 53-87.

Beuren, F.H., Gitirana, M., Ferreira, G., \& Miguel, P.A.C. (2013). Product-service systems : a literature review on integrated products and services. Journal of Cleaner Production, 47, 222-231. https://doi.org/10.1016/j.jclepro.2012.12.028

Chierici, E., \& Copani, G. (2016). Remanufacturing with upgrade PSS for new sustainable business models. Procedia CIRP, 47, 531-536. https://doi.org/10.1016/j.procir.2016.03.055

Clarkson, M. (1995). A stakeholder framework for analyzing and evaluating corporate social performance. Academy of Management Review, 20(1), 92-117.

Eisenhardt, K.M. (1989). Building theories from case study research. The Academy of Management Review, 14(4), 532-550.

Eisenhardt, K.M., \& Graebner, M.E. (2007). Theory building from cases: Opportunities and challenges. Academy of Management Journal, 50(1), 25-32. https://doi.org/10.5465/AMJ.2007.24160888

Ferguson, M.E., \& Toktay, L.B. (2006). The effect of competition on recovery strategies. Production and Operations Management, 15(3), 351-368. https://doi.org/10.1111/j.1937-5956.2006.tb00250.x

Ferguson, M., Guide Jr. V., Koca, E., \& Souza, G.C. (2009). The value of quality grading in remanufacturing. Production and Operations Management, 18(3), 300-314. https://doi.org/10.1111/j.19375956.2009.01033.x 
Ferrer, G., \& Ketzenberg, M.E. (2004). Value of information in remanufacturing complex products. IIE Transactions, 36(3), 265-277. https://doi.org/10.1080/07408170490274223

Ferrer, G., \& Whybark, D.D. (2000). From garbage to goods: Successful remanufacturing systems and skills. Business Horizons, 43(6), 55-64. https://doi.org/10.1016/S0007-6813(00)80023-3

Flynn, B.B., Kakibara, S.S., Schroeder, R.G., Bates, K.A., \& Flynn, E.J. (1990). Empirical research methods in operations management. Journal of Operations Management, 9(2), 250-284. https://doi.org/10.1016/02726963(90)90098-X

Fonseca, L.M., \& Ferro, R.L. (2016). Does it pay to be social responsible? Portuguese SMEs feedback. Intangible Capital, 12(2), 487-505. https://doi.org/10.3926/ic.712

Fonseca, L., Ramos, A., Rosa, Á., Braga, A.C., \& Sampaio, P. (2016). Stakeholders satisfaction and sustainable success. International Journal of Industrial and Systems Engineering, 24(2), 144-157. https://doi.org/10.1504/IJISE.2016.078899

Freemen, R.E., Harrison, J.S., Wick, A.C., Parmar, B.L., \& Colle, S.D. (2010). Stakeholder theory: The state of the art. Cambridge, United Kingdom: Cambridge University Press. https://doi.org/10.1017/CBO9780511815768

Gehin, A., Zwolinski, P., \& Brissaud, D. (2008). A tool to implement sustainable end-of-life strategies in the product development phase. Journal of Cleaner Production, 16(5), 566-576. https://doi.org/10.1016/j.jclepro.2007.02.012

Guide Jr., V. (2000). Production planning and control for remanufacturing: Industry practice and research needs. Journal of Operations Management, 18, 467-483. https://doi.org/10.1016/S0272-6963(00)00034-6

Guide Jr., V., Jayaraman, V., Srivastava, R., \& Benton, W.C. (2000). Supply-chain management for recoverable manufacturing systems. Interfaces, 30(3), 125-142. https://doi.org/10.1287/inte.30.3.125.11656

Hammond, R., Amezquita, T., \& Bras, B. (1998). Issues in the automotive parts remanufacturing industry - A discussion of results from surveys performed among remanufacturers. International Journal of Engineering Design and Automation - Special Issue on Environmentally Conscious Design and Manufacturing, 4(1), 27-46.

Hatcher, G.D., Ijomah, W.L., \& Windmill, J.F.C. (2011). Design for remanufacture: a literature review and future research needs. Journal of Cleaner Production, 19(17-18), 2004-2014. 
Ijomah, W.L. (2002). Model-based definition of the generic remanufacturing business process. University of Plymouth.

Ijomah, W.L. (2008). A tool to improve training and operational effectiveness in remanufacturing. International Journal of Computer Integrated Manufacturing, 21(6), 676-701. https://doi.org/10.1080/09511920701501779

Ijomah, W.L., McMahon, C.A., Hammond, G.P., \& Newman, S.T. (2007). Development of design for remanufacturing guidelines to support sustainable manufacturing. Robotics and Computer-Integrated Manufacturing, 23(6), 712-719. https://doi.org/10.1016/j.rcim.2007.02.017

Lind, S., Olsson, D., \& Sundin, E. (2014). Exploring inter-organizational relationships in automotive component remanufacturing. Journal of Remanufacturing, 4(1), 1-14. https://doi.org/10.1186/2210-4690-4-5

Lund, R.T. (1984). Remanufacturing: the experience of the USA and implications for the developing countries. Washington, D.C.: World Bank.

Ma, Y., Jun, H., \& Kim, H. (2011). Disassembly process planning algorithms for end-of-life product recovery and environmentally conscious disposal. International Journal of Production Research, 49(23), 7007-7027. https://doi.org/10.1080/00207543.2010.495089

Manzini, E., \& Vezzoli, C. (2002). Product-service systems and sustainability. United Nations Environment Program (UNEP), Division of Technology Industry and Economics (DTIE), Production and Consumption Branch, Paris.

Martin, P., Guide Jr., V., \& Craighead, C.W. (2010). Supply chain sourcing in remanufacturing operations: An empirical investigation of remake versus buy. Decision Sciences, 41(2), 301-324. https://doi.org/10.1111/j.1540-5915.2010.00264.x

Matos, S., \& Silvestre, B. S. (2013). Managing stakeholder relations when developing sustainable business models: The case of the Brazilian energy sector. Journal of Cleaner Production, 45, 61-73. https://doi.org/10.1016/j.jclepro.2012.04.023

Mont, O. (2002). Functional thinking: The role of functional sales and product service systems for a function-based society. Naturvårdsverket. Retrieved from: http://lup.lub.lu.se/record/956107

Mont, O. (2004). Product-serviec systems: Panacca or myth? International Institute for Industrial Environmental Economics, Lund University. 
Mont, O., Dalhammar, C., \& Jacobsson, N. (2006). A new business model for baby prams based on leasing and product remanufacturing. Journal of Cleaner Production, 14(17), 1509-1518. https://doi.org/10.1016/j.jclepro.2006.01.024

Mont, O., \& Tukker, A. (2006). Product-Service Systems: reviewing achievements and refining the research agenda. Journal of Cleaner Production, 14(17), 1451-1454. https://doi.org/10.1016/j.jclepro.2006.01.017

Neely, A. (2007). The servitization of manufacturing: an analysis of global trends. In 14th EurOMA Conference, Ankara.

Östlin, J., Sundin, E., \& Björkman, M. (2008). Importance of closed-loop supply chain relationships for product remanufacturing. International Journal of Production Economics, 115(2), 336-348. https://doi.org/10.1016/j.ijpe.2008.02.020

Platts, K.W. (1993). A process approach to researching manufacturing strategy. International Journal of Operations \& Production Management, 13(8), 4-17. https://doi.org/10.1108/01443579310039533

Reim, W., Parida, V., \& Örtqvist, D. (2015). Product-Service Systems (PSS) business models and tactics A systematic literature review. Journal of Cleaner Production, 97, 61-75. https://doi.org/10.1016/j.jclepro.2014.07.003

Sakao, T., \& Mizuyama, H. (2014). Understanding of a product/service system design: A holistic approach to support design for remanufacturing. Journal of Remanufacturing, 4(1), 1-24. https://doi.org/10.1186/2210-4690-4-1

Sherwood, M., Shu, L.H., \& Fenton, R.G. (2000). Supporting design for remanufacture through waste-stream analysis of automotive remanufacturers. CIRP Annals - Manufacturing Technology, 49(1), 87 90. https://doi.org/10.1016/S0007-8506(07)62902-3

Subramoniam, R., Huisingh, D., \& Chinnam, R.B. (2009). Remanufacturing for the automotive aftermarket-strategic factors: literature review and future research needs. Journal of Cleaner Production, 17(13), 1163-1174. https://doi.org/10.1016/j.jclepro.2009.03.004

Subramoniam, R., Huisingh, D., \& Chinnam, R.B. (2010). Aftermarket remanufacturing strategic planning decision-making framework: theory \& practice. Journal of Cleaner Production, 18(16-17), 1575-1586. https://doi.org/10.1016/j.jclepro.2010.07.022

Sundin, E., \& Bras, B. (2005). Making functional sales environmentally and economically beneficial through product remanufacturing. Journal of Cleaner Production, 13(9), 913-925.

https://doi.org/10.1016/j.jclepro.2004.04.006 
Susman, G.I., \& Evered, R.D. (1978). An assessment of the scientific mertis of action research. Administrative Science Quarterly, 23, 582-603. https://doi.org/10.2307/2392581

Tukker, A. (2004). Eight types of product-service system: Eight ways to sustainability? Experiences from Suspronet. Business Strategy and Environment, 13, 246-260. https://doi.org/10.1002/bse.414

Tukker, A. (2015). Product services for a resource-efficient and circular economy - A review. Journal of Cleaner Production, 97, 76-91. https://doi.org/10.1016/j.jclepro.2013.11.049

Wu, C.-H. (2012). Product-design and pricing strategies with remanufacturing. European Journal of Operational Research, 222(2), 204-215. https://doi.org/10.1016/j.ejor.2012.04.031

Wu, C.-H. (2013). OEM product design in a price competition with remanufactured product. Omega, 41(2), 287-298. https://doi.org/10.1016/j.omega.2012.04.004

Yin, R.K. (2009). Case study research: Design and methods (4th ed.). London, United Kingdom: Sage Publications, Inc.

Journal of Industrial Engineering and Management, 2017 (www.jiem.org)

Article's contents are provided on an Attribution-Non Commercial 3.0 Creative commons license. Readers are allowed to copy, distribute and communicate article's contents, provided the author's and Journal of Industrial Engineering and Management's names are included. It must not be used for commercial purposes. To see the complete license contents, please visit http://creativecommons.org/licenses/by-nc/3.0/. 